Article

\title{
Digital Transformation in the Chilean Lodging Sector: Opportunities for Sustainable Businesses
}

\author{
Antonio Farías and Christian A. Cancino *(D) \\ Department of Management Control and Information Systems, School of Economics and Business, \\ University of Chile 1, Santiago 8330015, Chile; anfari@fen.uchile.cl \\ * Correspondence: cancino@fen.uchile.cl; Tel.: +56-2-2978-3331
}

check for

updates

Citation: Farías, A.; Cancino, C.A. Digital Transformation in the Chilean Lodging Sector: Opportunities for Sustainable Businesses. Sustainability 2021, 13, 8097. https://doi.org/ $10.3390 /$ su13148097

Academic Editors: Marco

Opazo Basáez, Ferran

Vendrell-Herrero, Lorea Narvaiza Cantin and Barbara Motyl

Received: 1 June 2021

Accepted: 14 July 2021

Published: 20 July 2021

Publisher's Note: MDPI stays neutral with regard to jurisdictional claims in published maps and institutional affiliations.

Copyright: (C) 2021 by the authors Licensee MDPI, Basel, Switzerland. This article is an open access article distributed under the terms and conditions of the Creative Commons Attribution (CC BY) license (https:// creativecommons.org/licenses/by/ $4.0 /)$.

\begin{abstract}
The lodging industry increasingly relies on digital technology and innovations in various operations in order to develop a competitive strategy and improve their operational activities during the pandemic. Nowadays, digital transformation is a key element for business sustainability. This paper presents an industry case study involving four hotels or lodging companies operating in Chile which have successfully incorporated technology and new communication channels with their clients, carrying out a digital transformation that is key to the competitiveness and survival of their businesses. The results show that the impact of digitalization on sales and visibility of companies in the sector is huge; second, the effects of digital innovation on the management of key processes, both in the back office and in the front office, is very important; third, the incorporation of technology as a standard factor in order to be competitive in the industry is a key element; finally, the problems or obstacles that lodging companies must face in the process of implementing new information technologies. Without digital innovation, this sector would not have been able to survive in times of pandemic.
\end{abstract}

Keywords: lodging sector; hotels; digital transformation; digital innovations

\section{Introduction}

The COVID-19 pandemic has increased the need to innovate and generate a source of maintenance for operations, business models and jobs [1]. The latter has been particularly important in hotels in different parts of the world, which have experienced, due to the pandemic that has not yet ended, a decrease in demand, and they currently need to be visible and show availability at all times and places. In this sense, the incorporation of a digital transformation of these businesses has allowed them to develop innovations that provide the sustainability that these projects require [2]. It is precisely thanks to these innovations that millions of jobs and the viability of the sector have been maintained worldwide.

An extensive list of academic papers on Product-Service Innovation (PSI) show the cases of innovation in manufacturing companies that have changed or adjusted their way of competing in the markets [3-11] through the incorporation of services. All this literature, and its analyzed cases, are examples for other industries, where it is key to understand the need to innovate as a way to develop new competitive capabilities. In some markets, it is actually the way to develop sustainable businesses. For instance, the digital services industry has seen how, through digital innovation, it is possible to influence the purchase intention of consumers [1,2,12-15]. Likewise, other industries, such as retail, see it as a case of replicating the adaptive process necessary in PSI and have developed it in a particular way through examples of digital transformations [4,16,17].

The introduction of technology has allowed companies to manage their business processes more efficiently and smoothly [18] with regard to their operations, and to become more appealing from the customer's perspective when a business is advertised through social media [19]. The introduction of digital technology in business management has generated multiple benefits. Among them are an increase in productivity, a better experience 
and, therefore, greater customer loyalty, along with the possibility of accessing new markets $[14,20]$. In general, it is currently possible to identify a large number of technologies that can be defined as applications that deliver information services depending on the location of the user or the person offering the service [21]. The full potential of these new technologies is enormous, especially considering the millions of people using ubiquitous mobile devices, which are not only growing in popularity but also in permanent connection and as the main means of hiring services [22]. In that sense, it is noteworthy to mention technologies and applications that allow, among other things, managing marketing promos and customer notification [23] and also identifying neighborhood stores or the nearby sector where they are located $[24,25]$. This has caused a tremendous change for many sectors and industries where, through digital transformation, they have promoted the development of business sustainability. For [26], there are typology ranges from business sustainability, being important those who, along with worrying about the financial sustainability of the businesses, maintain the sustainability in the use of natural resources and also of the employment conditions for the workers and society in which the organization participates. In this sense, the digital transformation is supporting the relationship with the sustainability of businesses by allowing communities, and their workers, to maintain their jobs, good social conditions and support the good use of natural resources where they operate, since the existence of companies promotes economic and social development for the community. This relationship of innovation and sustainability is also an example seen at PSI. For example, Ref. [9] examined how the computer and electronics industry developed green servitization as a strategy for supporting flexible and sustainable supply chain management. Currently, it is essential for companies to develop a managerial mentality that allows digital transformation in operations. In that sense, Ref. [27] upholds the importance of IT and R\&D team structures for strategic decisions and to better exploiting firms' innovation capabilities.

The main goal of this study is to discuss the key elements and questions that account for the impact that digital transformation has on the way the lodging sector competes in a developing economy. In particular for the lodging industry, what are the necessary resources to innovate in the sector and incorporate elements of digital transformation? What are the barriers to digital transformation in the hotel sector?

This paper presents an industry case study involving multiple firms in the lodging sector in Chile. This qualitative study was developed through interviews with senior executives from four hotels or lodging companies operating in Chile. All of them have successfully incorporated technology and new communication channels with their clients, carrying out a digital transformation that is key to the competitiveness and business sustainability. This change in the development strategy has not only allowed companies to compete better, but also to be more sustainable over time. It has allowed them to maintain operational activities in their regions and communities, and thereby employ workers and the entire production network of those communities that develop thanks to tourism.

This analysis, where we see the characteristics and distinctive elements of each business, leads to at least four proposals or results arising from this study, in which specific guidelines are recommended for companies in the lodging sector, where digital transformations must be analyzed as a necessity and as an industry standard. Among these proposals, there is evidence of: first, the impact of digitalization on sales and visibility of companies in the sector; second, the effects on the management of key processes, both in the back office and in the front office; third, the incorporation of technology as a standard factor in order to be competitive in the industry; finally, the problems or obstacles that lodging companies must face in the process of implementing information technologies.

\section{Digital Transformations in Lodging Firms}

According to [2], the increasing dependence on digital technology is acknowledged in many industries, and tourism is no exception. In this sense, it is possible to define the digital transformation of companies associated with tourism, such as hotels, as a dynamic process 
that allows transforming the main activities of companies and their value propositions through the effective use of digital technologies.

With regard to logging firms, different digital tools have changed the way business is done. Social networks, for example, have made it possible for guests in specific accommodations to share their experience with potential customers from different parts of the world, generating a new scenario to boost the company's visibility (awareness) and brand [28]. Social networks, as a means of communication and lodging service marketing, Internet and mobile applications, as digital channels that facilitate service marketing and customer feedback, plus information technology that enables the optimization of administrative processes (reservations, service payment, passenger check-in and check-out, etc.), improve not only consumer experience and company visibility but also the company's back office activities, thus providing an opportunity to improve its performance. Naturally, among the factors that account for digital transformation, there are also limitations or restrictions to its development and implementation, which will also be considered barriers to digital transformation in this work.

On the other hand, the use of information and communication technology (ICT) has led to ongoing innovation in lodging services, thus better catering to the needs of different client niches [29-31], while at the same time improving the efficiency and reliability of lodging firm operations $[2,13,32]$.

\subsection{Digitalization and Business Innovation in Hotels}

Digital transformation could be understood as the dynamic adjustments observed in the core activities, processes and revenue models of firms through the effective use of digitalization or incorporation of digital technologies [2]. Digital transformation has become essential for companies in any sector, including the lodging sector, to achieve business objectives, improve service quality, reduce costs and gain a competitive advantage. Currently [28-30], communication supported by hotel digitization is an integral element of the service experience. The use of digital solutions can cover various contexts, from actions to interact with hotel guests, improved visual communication with the use of virtual reality, functions on hotel websites or the incorporation of innovations in operational processes of each firm.

For [30], digitalization in business affects the marketing and management of tourism destinations. In the lodging sector, new information technologies foster business innovation, contribute to sustainability, improve the accessibility of hotels and landmarks and increase the productivity, profitability and quality of services. Digital transformation in the lodging sector could include artificial intelligence and robotics that would result in jobs shifting from human to nonhuman employees, thus transforming tourism and hospitality from a labor-intensive industry into a technology-intensive industry [2].

According to [13], a series of assumptions must be reviewed when thinking about the digital transformation of companies, since the vision of the technologies of the last century should not be the same as in the current digital world. These outdated assumptions include the following: customers value human touch; the limit of how far we can automate our operational processes has been reached; working as an integrated company will slow us down and stifle innovation; and the strategic assets that brought us success in the physical world will also be valuable in the digital environment. It will be necessary to review the adjustments that digitization brings about the value proposition to customers, the changes and improvements in key business processes and the use of critical and competitive resources. In the case of the lodging sector, these assumptions could limit the firms' ability to innovate.

\subsection{Benefits of Digitalization in Lodging Sector}

Furthermore, from the customer's perspective, technology has facilitated the development of new hosting options, thus making access to the market more appealing to new competitors (Airbnb, HomeAway, Wimdu). As a result, the industry has become much 
more competitive, forcing companies in the sector to improve their performance in order to boost revenues and profitable growth [33].

The benefits that technology brings to the hospitality business are so important that different countries have developed training programs regarding the use of information technology for this type of business. In Chile, for example, and due to the significance that tourism has as a major source of income for the country, the government has developed a training program for tourism companies in general, and for accommodation companies in particular, in different regions of the country, focusing its efforts on small and medium enterprises in the industry [34].

As a result, certain businesses have become more appealing, particularly those in the lodging business, which not only makes the activity livelier but also reaches a potential market of a much wider range of consumers. For [35], the interest in the buyer-supplier relationship is very important because it helps to mobilize the time, collaborators and any financial investment that a company makes more effectively when it understands its demand better. For [36], the transformation of the organizational practices in a business environment adjusted to the use of digital media, including social media, allows to manage not only activities facing the customer, but also behind the counter (back office). For example, research is being carried out on aspects such as the active management of suppliers with social media, which generates significant contributions [37]. This active management is also fundamental in lodging companies, where the benefits of incorporating new technologies and applications that improve customer satisfaction and greater demand also generate positive effects on all back-office activities that have this type of business. This allows both to generate a particular value proposal to a greater number of potential customers, and also to make the value chain of the firm more efficient.

Digitalization and business innovation is key for the competitiveness of the lodging sector, although hotel firms in Chile are lagging behind in using the potential that is offered by new technologies and digital tools. It is precisely the above, which motivates the present work. This paper studies the characteristics of hotels in Chile and their relationship with digitalization and digital transformation as a way to maintain competitiveness, value proposition for customers and the development of key business processes in the hotel industry in Chile.

\section{Method}

The research methodology used in this work is through an industry case study involving multiple firms in the lodging sector in Chile $[3,38,39]$. This qualitative study was developed through interviews with senior executives from four hotels or lodging companies operating in Chile. According to [40], case studies have been an essential form of research in the social sciences and particularly in management. One of the objectives of this case study is to explain empirical results by identifying a set of stable and independent elements that, within a specific context, allow setting, in an exploratory way, possible causal relationships between relevant variables [41].

Data were collected through face-to-face interviews conducted in the first semester of 2020 using a semi-structured questionnaire designed for the study. The questionnaire contains questions for three clearly identified stages: (1) The business situation prior to the digital transformation process; (2) the digital transformation process itself; and (3) the situation after the digital transformation process. The data collected will be processed using the content analysis technique.

Four cases of companies in the lodging sector in Chile are studied, particularly hotels located in the southern part of the country, where tourism is an important activity for economic development. The choice of this group of hotels was for convenience. Its executives are close to the university of academics who write this work. Likewise, the community and the tourist sector depend on the operation of these hotels, which allows them to be defined as sustainable businesses for each region where they operate. 
It is important to analyze the four cases, as two of them are medium-sized hotels within the Chilean capital, which, despite their challenge of sustaining greater competitiveness, have shown a significant investment in new technologies (web services and apps) and social networks to reach their customers (Instagram, Facebook, Twitter, among others). The other two hotel companies are large international chains operating in Chile. In order to ensure the reliability of the information, we will keep their names confidential, using fictitious names for each one. For example, the two Chilean hotel companies, one of them being a private, non-family-owned hotel, will be called Hotel AB. The second Chilean hotel, which is a family business, will be called Hotel CD. In contrast, the hotels belonging to international chains that can be defined as large hotels have been named Hotel EF and Hotel GH in this paper. The following Table 1 summarises the main characteristics of each hotel in terms of size, type of property and national or international scope. The previous information is used to identify some of their characteristics. The interesting thing about this study sample is that in all cases, the managers declare that their businesses have enthusiastically embarked on a digital transformation to make their hotel more competitive.

Table 1. Hotels' main characteristics.

\begin{tabular}{ccccc}
\hline & Hotel AB & Hotel CD & Hotel EF & Hotel GH \\
\hline Number of stars & Between 2 and 3 & Between 2 and 3 & Between 4 and 5 & Between 4 and 5 \\
Number of rooms & Fewer than 20 & Fewer than 20 & More than 100 & More than 100 \\
SMEs or Large Size & SME & SME & Large & Large \\
National or international chain & National & Nacional & International & International \\
Family or non-family business & Non-Family & Family & Non-Family & Non-Family \\
\hline
\end{tabular}

The questionnaire applied provides a series of variables of interest for the literature on lodging firms. These variables are related to four major areas of activity and impact related to digital transformation in different areas of lodging business management:

1. The impact of digitalization on sales and the visibility of companies in the sector.

2. The effects on the management of key processes, both back office and front office.

3. The incorporation of technology as a standard factor in order to be competitive in the industry.

4. The problems that lodging companies must face while implementing new information technologies.

After studying the behaviour of each of the case studies based on the previously mentioned variables, this paper presents a discussion of the results and implications for researchers and practitioners of each proposal analyzed.

\section{Results}

This section presents the findings from interviews with key managers from four longing companies operating in Chile. As shown in Table 1, the EF and GH Hotels are two large international hotels or chains, where the highest numbers of rooms per hotel and the most stars in each one are highlighted, a feature that depends on the services provided by each company, which include the restaurant, gym, sauna and swimming pool, among others. However, in the cases of the $\mathrm{AB}$ and $\mathrm{CD}$ hotels, they are much smaller in size, in number of rooms, services and, of course, the number of stars.

In the case of the medium-sized hotels, $\mathrm{AB}$ and $\mathrm{CD}$, two types of digital transformations are carried out. Firstly, the incorporation of internet and social network solutions to make each hotel visible anywhere in the world in terms of its service offerings and availability of rooms (hotel's webpage online booking; central reservation systems). In this case, there are relevant solutions of channel management that control reservations from different platforms such as booking.com, Expedia, lastminute.com, Airbnb, among others. Secondly, service automation solutions are implemented, for example, front desk operations solutions and tools for accessing rooms through digital mechanisms (electronic keys, 
RFID solutions, among others) or electronic access to service rooms such as restaurants, gyms or spaces such as office guest workstation (for high-speed internet connection or printer use). According to the interviewees of smaller hotels, they look closer to an initial stage of digital transformation.

"We are happy to have advanced in digital transformation in front-desk activities, particularly with central reservation and channel management systems. In the future we will evaluate other more sophisticated systems and applications" (CEO Hotel CD).

In the case of the largest companies, EF and GH, they had already incorporated solutions similar to the previous ones (front desk solutions and central reservation systems) and the focus is now on the implementation of PMS (Property Management Systems), which implies developing greater interactions among the various areas of the business, such as back-office management, housekeeping, reports and analytics, revenue management, customer data management and CRM and point of sale services. The automation of services is also important for this group of large hotels (automation of accesses, services, connections with the guests' own mobile phones, etc.).

"In our case, advances in digital transformation affect our core business processes, both to better understand our frequent customers, and to manage each back-desk operation according to the demand of our guests. We are in a higher stage of digital transformation of the sector. For example, if we do more business analytics we will get to know our client better and what he or she really values." (CEO Hotel EF).

Table 2 shows the impact of digitalisation on sales and visibility of companies in the sector as stated in the interviews for each hotel.

Table 2. Digital transformation, sales and awareness.

\begin{tabular}{lccc}
\hline & Hotel AB & Hotel CD & Hotel EF
\end{tabular}

Black circles "O "indicate a positive impact on the analyzed variable; White circles "O"indicate a negative impact on the analyzed variable; Pattern circles " $"$ " indicate an evolution from a short-term negative impact to a long-term positive impact.

The impact of digital transformation (DT) on the sale and visibility of services is diverse, depending on each case study. Although all of them state that in the long term they have seen improvements in their financial results, in the case of Hotel CD, the investment in DT did not seem to be successful at first, and on the contrary, the greater investment resulted in significant costs which were only recovered in the long term. In terms of increased sales, the large EF Hotel is interesting, stating that sales have not necessarily increased since this hotel was already well-known and its strong reputation allowed it to have a good occupancy rate. In terms of operational costs, the advantage and perceived cost improvement of incorporating more technology is evident for larger companies. They manage to identify and project the behaviour of their costs by having more information about the guests that will visit their facilities, which, due to economies of scale, they are able to observe as an important advantage in costs. In the case of the smaller hotels, the impact on one of them, Hotel $\mathrm{AB}$, occurred over time, becoming positive after adjustments regarding personnel and the new technology used. In the case of Hotel CD, the family nature of the company prevented it from experiencing cost improvements due to the new technology. Finally, in all the case studies, it appears that there is greater visibility of each business and therefore a greater number of queries in the various communication channels. 
Table 3 shows the impact of digitalization on the management of both key front office and key back-office processes as stated in the companies interviewed.

Table 3. Digital transformation and business process management.

\begin{tabular}{ccccc}
\hline & Hotel AB & Hotel CD & Hotel EF & Hotel GH \\
\hline Better customer perception & & & \\
Fewer mistakes in processes & & & \\
Improvements in purchased goods & & & \\
Better relationship with suppliers & $O$ &
\end{tabular}

Black circles " 1 "indicate a positive impact on the analyzed variable; white circles " $\bigcirc$ "indicate a negative impact on the analyzed variable.

Table 3 shows that the business process management in all the hotels, regardless of their size, has improved in terms of the customer perception of the service characteristics; fewer errors in the processes, which range from registering guests, scheduling stays and forecasting room occupancy, among others; likewise, it improves the coordination of logistical and operational activities in relation to room cleaning, infrastructure maintenance, and compliance with safety and hygiene plans. With regard to managing the purchase of supplies for operations, it is striking that everyone states that there is a better purchase of supplies, even though only the large companies, Hotel EF and Hotel GH from large international hotel chains, manage to generate a better relationship with their suppliers. They point out that it is the size of their purchases that allows them to have an important bargaining power, which small hotel companies do not report. Hence, the latter do not see significant improvements in their relationship with suppliers.

Table 4 shows the impact of digitalization on the incorporation of technology as a hygienic factor in order to be competitive in the industry as stated in the interviews.

Table 4. Digital transformation and competitiveness.

\begin{tabular}{l}
\hline \\
\hline Leader or follower in DT of sector \\
Takes years to invest in DT \\
Investment in DT is higher than \\
sector average \\
The hotel is more competitive after \\
investing in DT \\
$\begin{array}{l}\text { Black circles "O "indicate a positive impact on the analyzed variable; White circles "O"indicate a negative } \\
\text { impact on the analyzed variable. }\end{array}$
\end{tabular}

The competitiveness of the company or hotel under analysis following their digital transformation was measured in several aspects. First, only two hotels claimed to be leaders in their sector, and according to their size, they invested more than the competition in new technologies. It was interesting to see that it was not necessarily the largest that led, as was the case of Hotel GH. However, in the case of the other large hotel, Hotel $\mathrm{EF}$, it was pointed out that they invested in DT because the competition also did, and they realized that they could be left behind, that is, lagging behind, if they did nothing. Likewise, Hotel AB joined the trend in DT due to market pressures. The cases of Hotel CD and Hotel GH were different, as they led the way in their respective segments in terms of investment. Of course, the large companies did not take more than a year to invest in technology since there was a trend in DT. The same applies to Hotel CD. Naturally, smaller hotel companies invest much less than the industry average in DT. The relevance of the information concerning this point is that in terms of competitiveness, DT is only seen as a 
distinguishing factor for smaller companies. Large companies, on the other hand, do not see it as a distinctive factor of competitiveness, but as an industry standard to be met.

Table 5 shows the impact of digitalization on the problems that lodging companies encounter in the process of implementing new information in companies in the industry as stated in the interviews.

Table 5. Barriers to digital transformation.

\begin{tabular}{ccccc}
\hline & Hotel AB & Hotel CD & Hotel EF & Hotel GH \\
\hline Investment cost limits greater DT & & \\
Hotel staff was prepared for DT \\
Resistance to change was high \\
$\begin{array}{c}\text { among employees } \\
\text { Training was sufficient and key to } \\
\text { align staff }\end{array}$
\end{tabular}
impact on the analyzed variable.

Finally, Table 5 shows the obstacles that the companies under study had in their quests to incorporate technologies into their businesses. In the case of the largest companies, the greater investment in DT was not a major problem to be tackled. However, for smaller hotels it was different, even if opinions differed. Regarding Hotel CD, they considered it as an investment they were willing to develop and that they valued. The investment in Hotel $\mathrm{AB}$ affected the company's cash flow, hence they were concerned about the investment. It is interesting to note that in all cases, the interviewees declared that the employees or staff at their hotels were not prepared for a digital transformation. Lack of technical knowledge in languages, in the use of new technological platforms, of communication and of social networks in general fostered great resistance to change on behalf of the employees. It was only in the case of the family business, Hotel CD, that there was not much resistance to change, since the very family nature of the company allowed for alignment on this investment.

As stated by the interviewees, greater training and investment in human capital, especially in the development of skills, made it possible, at least in the cases of the $C D$, $\mathrm{EF}$ and GH hotels, for people to be aligned with the objectives of each hotel in terms of promoting the use of new technologies to enable the digital transformation of the frontand back-office operations of each hotel. However, training was not sufficient for Hotel AB, and staff had to be replaced.

Undoubtedly, the four cases analyzed are interesting and the results of each interview are very useful to compare in order to generate recommendations for practitioners and researchers concerning the recommended developments in the hotel sector in developing countries in their challenge to incorporate new technologies and further digital transformation in their operations.

\section{Discussion}

It is possible to identify at least four proposals from the results of this multiple case study, which we intend to test in future research, ideally through statistical or econometric methodologies, in order to deepen the analysis of key variables of lodging firms. These proposals are: Digital transformation improves the performance of lodging firms by improving both sales and service awareness; Digital transformation facilitates the management of the business processes inherent to the lodging companies; Regarding competition, Digital Transformation is imperative among lodging firms [42]; Digital Transformation in the lodging sector must overcome a set of practical problems in order to obtain the stream of benefits deriving from the new way of doing business. 


\subsection{Digital Transformation, Sales and Awareness}

In order to compete successfully, every company must define an engaging value proposition for its customers $[43,44]$ and, at the same time, create a business model that allows it to obtain the necessary revenue in order to be profitable. The value proposition must address customers' needs in multiple areas within their experience, such as response time, access to products and / or services offered by the company, price, omni-channel, etc., Ref. [45] and must work to differentiate itself from its competitors in at least one of these aspects. However, even when the value proposition is appealing to the customer segment to which it is directed, the income that the company can generate also depends on other key factors; among them are the advertising required to inform the customer and promote the products and services offered (awareness), access to the goods offered by the company, the sales process itself and how the company provides customers with these goods and how it builds a profitable relationship with the customer over time, among others.

In the lodging sector, technology has allowed the companies under analysis to use different tools to highlight and promote the services they provide. Both the Internet and social networks (social media) have become the preferred media for most of the clients of the companies analysed, even considering that they represent the industry in general, in order to know the different options offered [46]. If a client wants to travel to a certain place, either for pleasure or for business, they simply need to enter a search engine and find out about all the accommodation options offered by the market, thereby making the company visible to millions of people around the world. At the same time, a good use of the Internet and social networks allows the company to promote their service [46], thus influencing the purchasing attitude of the customer segment to which its value proposal is directed, at a lower cost. Internet promotion allows the company to show, at a low cost, the services offered and the recommendations (ratings or scores) of the users regarding these services. Something similar occurs with social networks where, in addition to the advantages offered by the Internet, the company can encourage word of mouth among those who have used the services and potential future customers [47].

A website with the appropriate usability can significantly improve customer access to the services offered by the company. From the user's point of view, having the possibility of booking and paying for the service virtually improves their shopping experience significantly, even more so if the company offers them different means of payment [48]. Meanwhile, for the company, the sales process is simplified and there are fewer mistakes, which, in turn, reduces the customer's uncertainty as to whether the accommodation will be available upon arrival at their destination.

Technology can also facilitate the customer's access to the accommodation service itself. For instance, hotels provide users with a virtual access codes to the hotel and the room they have booked, thus simplifying the check-in and check-out process. Another example relates to the use of applications to open a door to the assigned room and to access other services offered by the hotel [49]. In both cases, the company speeds up its processes for the client and reduces the costs of the operation significantly. All of the above occurred mainly in the two largest hotels analyzed in this paper.

Meeting the value attributes that the company has promised its customers makes it more likely for them to use the accommodation whenever necessary. In other words, a better hotel experience is more likely to generate greater customer loyalty, which is likely to lead to a stable revenue level and therefore less uncertainty regarding the company's competitive position in the future. Customer loyalty, thus achieved, provides a valuable opportunity to make the relationship profitable over time, using information technologies that enable the monitoring of the user's purchasing behaviour in order to customise the offer of new services and, therefore, extract more revenue from already loyal customers [50].

\subsection{Digital Transformation and Business Process Management}

Providing an appealing value proposition is not sufficient; it also requires all hotels to adequately implement the strategy supporting it. A good application of the strategy 
requires efficient and effective management of the business processes that allow the implicit promise of the value proposal to be fulfilled in a profitable manner. In other words, the management of each process must comply with the outputs for which it has been designed and, at the same time, should do so with the least possible resource consumption [51].

For organizations to reap the full benefits of the digital transformation, they must undergo various stages of development [52]. In the case of hotel companies, this is key. In the first stage, incorporating technology aims at performing a task in a more agile and efficient manner $[53,54]$; the application of standard information and communication technologies (ICTs) available in the market is standard practice at this stage [55]. In a second stage, in order to achieve a better economic performance, it is necessary to integrate the different business processes that operate transversally in the organization, both from a technical point of view (inter-operability) and from the interdependence of the different functions that exchange information [56].

The benefits of digital technology are not fully achieved despite the fact that processes are integrated across the board. To move forward, it is necessary to redesign processes in line with changes in competitors' business processes, especially those processes related to new ways of doing business in those companies that successfully join the industry [57]. For this reason, many of the hotels analyzed required employee training in the use of the new ICTs, and otherwise, hiring new personnel with previously acquired knowledge.

The next phase aims to redesign the organization's business processes in relation to those of other companies that constitute its operations network (for example, suppliers and distributors of hotel inputs); the purpose here is not simply to share information, but to integrate key processes that are part of the industry's value chain, so that the economic performance of the hotel companies in the network improves significantly [58]. Finally, a full digital transformation for the type of company analyzed (with the associated economic benefits) should ease the outsourcing of different processes (through joint ventures, alliances partnerships and the like), given that digital technology facilitates the coordination and control of the processes performed by external companies [59].

Business processes for the lodging sector, and also for other sectors, can be classified into those processes that the company carries out in front of the customer (front office) and those that it carries out internally (back office) in order to be able to respond to the customer when he needs it. Some typical procedures within the hospitality sector are the reservation of accommodation, the sales process itself and the activities associated with check-in and check-out, among others. In terms of internal processes, activities associated with maintenance and housekeeping services, supplier management, processing and analysis of business information, and marketing activities are key to good economic performance in the medium and long term.

As previously discussed, key customer-facing processes are supported by information technologies; currently, the focus is on moving towards the adoption of smart technologies [31]. Automated booking and sales through the company's website or the application (app) it has developed (application development applies mainly to large companies), checkin, check-out, room entry using the telephone and monitoring any services in addition to accommodation are managed on the basis of an information system containing customer data and the services hired.

Concerning the internal processes, the lodging companies use standard software available on the market to manage and control their own operations and integrated information systems to connect the business management with their suppliers and other companies that offer complementary services to accommodation itself, such as tourism agencies, restaurants and travel agencies.

\subsection{Digital Transformation and Competitiveness}

In order to maintain a solid competitive position over time, every company must face two challenges with regard to the customer: (1) to be eligible and (2) to be chosen. In the first case, in order to be eligible, the company must possess the resources and skills 
necessary to manage the business in such a way as to be able to offer a product and/or service that meets the required standards within the strategic group in which it competes. In the second case, to be chosen by the client, the company must not only comply with industry standards, which is not enough, but the company must also develop skills that allow it to deliver a differentiating value proposition, innovating constantly in order to stay ahead of its competitors [60].

To qualify in the lodging sector today, as in any other industry, it is imperative for companies to incorporate digital technology into business management because of the impact it has on their economic performance [42,61]. On the one hand, digital technology allows the company to reach more customers (awareness), reduce costs, manage the relationship with its suppliers more smoothly and participate in networks with companies that offer complementary services to accommodation [62]. On the other hand, it enables the company to provide the client with a better standard of service [63], facilitating the various transactions that clients must carry out when interacting with the company. In an industry where accommodation alternatives are varied and abundant, the client is in a position to demand compliance with the service standard provided by companies that have incorporated digital technology into the management of their business, so that their expectations are met [42].

A lodging company must go beyond standard compliance to be chosen. To overcome this challenge, it is necessary for the company to use digital technology strategically, creating and co-creating value for its customers in an innovative and sustained way [64], while developing new business models that allow it to successfully deal with both the traditional accommodation service offered and new ways of providing accommodation, such as peer to peer accommodations, collaborative consumption and the like [32]. In this scenario, the company must not only have incorporated digital technology into its business management or have the skills to use it efficiently and effectively but must also develop the skills to become a digital 4.0 company [65].

Despite the importance of incorporating digital technology for lodging companies, its full implementation in small and medium enterprises has not been as fast as business dictates. In this sense, and even though many of these companies have the technology available on the web, its use is focused on managing the basic transactions that the operation of the accommodation service requires. Consequently, various governments have developed digitalization programs for companies in the sector, so that they can take full advantage of the benefits of digitalization and thus be competitive. However, even the majority of large companies that have rapidly adopted the technology available on the market have not been successful in developing competitive advantages that are sustainable over time [66].

\subsection{Barriers to Digital Transformation}

As it is possible to see in [6] for their analysis of barriers related to capturing the value of advanced services and digitisation in the road transport industry, in this study of the lodging sector, it is interesting to analyze the barriers regarding digital transformation. As with all transformation processes, the adoption and optimal use of digital technology in the lodging sector must face barriers that will need to be overcome with the agility that the competitive environment demands [42]. Within these challenges, two stand out: (1) the process of cultural change, and (2) the acquisition and/or development of the competencies or skills needed to achieve a digital transformation that will allow the company to maximize the benefits derived from it [67].

Culture provides the members of an organization with a framework to represent their behaviour. The people working in the organization understand which behaviours are expected of them and which are not [68], deriving from a set of shared beliefs and values. Therefore, culture defines the way in which tasks are carried out in the organization and justifies, from a value point of view, the relevance of such behaviour [5,69]. From an instru- 
mental perspective, a strong culture aligns employee behavior towards the cost-effective fulfilment of the value proposition that the organization provides to its customers [70].

While a strong culture is an important asset to facilitate the implementation of the organization's defined strategy, it is less so when it is imperative to change this strategy to remain competitive in the industry. A change in digital strategy requires a change in organizational culture [69]. However, the need for cultural change creates uncertainty among employees, which causes resistance towards developing the behaviour that the new reality demands [71]. On the one hand, the employees are not certain whether the change that takes place will allow the company's objectives to be achieved and, therefore, its continuity over time. On the other hand, there is no certainty that, in the new scenario, their skills will allow them to maintain their position within the organization. In short, the change of paradigm puts their well-being at risk.

Ref. [72] proposes different mechanisms to carry out a process of dynamic cultural change. The first of these relates to the role that the leader of the organization should play by communicating to all employees the urgent need to change the way the business is managed in order to ensure its continuity. As discussed above, in the case of the lodging sector, the incorporation of digital technology is vital for companies to remain competitive. Although this may seem obvious, the leader must communicate this time and again, and through all means available to him or her.

The type of leadership is also important. Although the literature describes several types of leadership, the distinction between transactional and visionary leadership becomes especially relevant regarding cultural change. In short, transactional leadership focuses on effectiveness and efficiency in the development of the tasks involved in the business operation. The transactional leader focuses primarily on achieving the goals defined for a given period. Visionary leadership, on the other hand, consists of looking ahead, promoting an attractive and realistic vision of the organization in the future [73]. Without neglecting the results of the business in a given period, the visionary leader is concerned with the competitive position of the company in the medium and long term, developing the competencies that will be required in the future [70]. In addition to permanent communication and visionary leadership, an effective cultural change requires incentives aligned with new performance. It will be very difficult for employees to internalize new behaviors if old ones are still being rewarded [74].

Another fundamental challenge for a successful digital transformation is the acquisition and/or development of the competencies and skills required at each and every hierarchical level of the organization. One of the main problems that managers have to solve in this regard is related to the tension that arises from having to, on the one hand, continue exploiting existing skills and, on the other hand, developing the digital skills needed to compete successfully in the new environment $[75,76]$.

In this scenario, managers must accurately identify the core competencies required to fully realize the potential of the digital transformation [5]. At the same time, they must discern whether these competencies can be developed internally or if the company can attract talent from the labour market. Finally, they must identify the employees who are willing to adjust to the new digital scenario and inspire others to integrate technology into their work in a productive way [77].

This means that for a lodging company to truly become a digital company, it is necessary to have appropriate technical, managerial and strategic competencies in order to manage and develop the business processes that support a strong competitive position in the future [78].

The future in the lodging sector is already here, as discussed above, so company staff urgently require new skills. In the case of technical skills, acquiring them does not seem particularly complex, either through recruitment or training. However, the new profile of the employee does not only require technical skills but also learning new forms of social interaction that using new technologies involves (embedded); at the same time, 
they must develop the ability to constantly learn in a scenario where technology upgrade is continuous and hectic.

Regarding the managerial and strategic skills needed for a successful digital transformation, it is necessary to develop transformational leaders, that is, the type of leader who stimulates the development of his or her subordinates and their commitment to the organization's values, showing them how important they are as key actors in achieving the organization's objectives and aligning their behavior and performance around the achievement of those objectives [79]. The successful transformational leadership also requires communicating frequently with subordinates and being in tune with the available digital media [63], empowering employees in order to transform them into agents of change and enabling them to develop the skills that the organisation will need in the future $[65,69]$.

\section{Conclusions}

The academic literature on Product-Service Innovation (PSI) shows cases of innovation in manufacturing companies that, through the incorporation of services, change the way they compete in markets. This dynamic of innovation is an example not only for manufacturing companies, but even service companies. This example of PSI in manufacturing invites other industries, such as hospitality, to evaluate innovation mechanisms for their sector. In particular in the hotel industry, this mechanism has been through digital innovations that allow transforming the front and back desk activities in each company. In this article we have presented an industry case study with four successful hotel companies that have implemented information and communication technologies to support their operations, attract more clients and support a business strategy in accordance with their respective value proposal. This digital transformation in the hotel industry has made it possible to survive in times of pandemic, maintaining the sustainability of projects in uncertain environments, collaborating with the employment of thousands of people and allowing a production and logistics chain to keep businesses open in different cities of the world. In this study and in the choice of the companies analyzed, it is interesting that, regardless of their size (two were large hotels and two were medium-sized hotels), all companies achieved business sustainability despite being threatened by market conditions with the COVID-19 pandemic. Without a digital transformation, these firms would not only have stopped operating, but also would have further decreased tourism in the cities where they operate, the care of certain national parks that depend on the visit of tourists and, of course, hiring workers who depend on this industry.

Several results and discussions for researchers and practitioners emerge from this analysis that we believe are essential for further study.

\subsection{Managerial Implications}

Firstly, digital technology generates various opportunities for companies (including lodging companies) to improve their performance and thus become more competitive, in a rapidly changing environment. However, to fully obtain all the benefits derived requires a transformation process that is complex and difficult to manage. For a digital transformation to be successful, it must allow companies to not simply catch up with their competitors but to improve performance in a sustained manner over time. In this article, it was interesting to see how in the smaller hotels, although they decided to invest in technology alongside the larger companies, the benefits of the digital transformation were not only experienced by reaching an industry standard, but they went further, enhancing their value proposition and improving their business performance in the long term. In other words, for the smaller and medium-sized hotel companies in reality, the digital transformation brought significant benefits.

Achieving a successful digital transformation has proven, in practice, to be a challenge even for multinational companies that have the resources and experience to adapt their strategies to the changing demands of the environment. In fact, according to studies by the consulting firm McKinsey, less than $30 \%$ of companies that have initiated a digital 
transformation process have had sustained success over time [66]. Furthermore, the success rate of technology companies (companies belonging to what are known as "digitally savvy industries" (high tech, media, telecom, etc.) does not exceed $26 \%$. Thus, in the case of large hotel chains, the experience of digital incorporation is linked to reaching a standard rather than being a distinguishing factor. The choice that clients make for these companies depends on other factors, which range from the delivery of complementary services, benefits for partners and companies and customer retention programs, among others.

The present work shows the importance of different factors involved in achieving a successful digital transformation. It is precisely the above that arises from this work, highlighting three key resources that must be incorporated to support digital transformation: transformational leadership committed to a strategic approach, a cultural change in each company and the development of new skills required to compete in the digital age (industry 4.0) [15]. Likewise, work must be done in four areas of action that allow the digital transformation in the hotel sector. Firstly, the impact of digitization on sales and visibility of companies in the sector. Secondly, the effects on the management of key processes, both in the back office and in the front office. Thirdly, the incorporation of technology as a standard factor to be competitive in the industry. Finally, the problems or barriers that hosting companies must face in the process of implementing new information technologies.

\subsection{Limitations and Future Research Directions}

Considering the exploratory nature of this research, and the limited number of cases analyzed, we recommend not generalizing the present results, as it is necessary to carry out confirmatory research that studies the real impact of digital transformation supporting the competitiveness and business processes of companies in the hotel sector in developing countries and the world. Some of the objectives of this study are to encourage the development of future research by researchers in hotel business management in order to complement this case analysis with econometric frontier methodologies, which will allow for the analysis of a larger sample of hotels and to compare the performance of these companies in their journey towards the digital transformation. This will allow a better understanding of whether there is a real impact of information and communication technologies in supporting the competitiveness and development of the sector.

Author Contributions: Conceptualization, A.F. and C.A.C.; methodology, A.F. and C.A.C.; validation, A.F. and C.A.C.; formal analysis, A.F. and C.A.C.; writing-original draft preparation, A.F. and C.A.C.; writing-review and editing, A.F. and C.A.C. Both authors have contributed equally to conceptualizing, data collection, analysis and the writing of the paper. Both authors have read and agreed to the published version of the manuscript.

Funding: This research received no external funding.

Conflicts of Interest: The authors declare no conflict of interest.

\section{References}

1. Gregurec, I.; Tomiçic-Furjan, M.; Tomiçic-Pupek, K. The Impact of COVID-19 on Sustainable Business Models in SMEs. Sustainability 2021, 13, 1098. [CrossRef]

2. Alrawadieh, Z.; Alrawadieh, Z.; Cetin, G. Digital transformation and revenue management: Evidence from the hotel industry. Tour. Econ. 2021, 27, 328-345. [CrossRef]

3. Bigdeli, A.; Bustinza, O.F.; Vendrell-Herrero, F.; Baines, T. Network positioning and risk perception in servitization: Evidence from the UK road transport industry. Int. J. Prod. Res. 2018, 56, 2169-2183. [CrossRef]

4. Galera-Zarco, C.; Opazo-Basáez, M.; Marić, J.; García-Feijoo, M. Digitalization and the inception of concentric strategic alliances: A case study in the retailing sector. Strateg. Chang. 2020, 29, 165-177. [CrossRef]

5. Larjovuori, R.L.; Bordi, L.; Mäkiniemi, J.P.; Heikkilä-Tammi, K. The role of leadership and employee well-being in organizational digitalization. In Proceedings of the 26th Annual RESER Conference, Naples, Italy, 8-10 September 2016; p. 1141.

6. Schroeder, A.; Galera Zarco, C.; Baines, T.; Ziaee Bigdeli, A. Barriers to capturing the value of advanced services and digitisation in the road transport industry. In Proceedings of the Spring Servitization Conference SSC, Manchester, UK, 16-17 May 2016.

7. Calle, A.D.L.; Freije, I.; Ugarte, J.V.; Larrinaga, M. Measuring the impact of digital capabilities on product-service innovation in Spanish industries. Int. J. Bus. Environ. 2020, 11, 254-274. [CrossRef] 
8. Sánchez-Montesinos, F.; Opazo-Basáez, M.; Arias-Aranda, D.; Bustinza, O.F. Creating isolating mechanisms through digital servitization: The case of Covirán. Strateg. Chang. 2018, 27, 121-128. [CrossRef]

9. Maric, J.; Opazo-Basáez, M. Green servitization for flexible and sustainable supply chain operations: A review of reverse logistics services in manufacturing. Glob. J. Flex. Syst. Manag. 2019, 20, 65-80. [CrossRef]

10. Seclen-Luna, J.P.; Moya-Fernández, P.; Pereira, A. Exploring the effects of innovation strategies and size on manufacturing firms' productivity and environmental impact. Sustainability 2021, 13, 3289. [CrossRef]

11. Seclen-Luna, J.P.; Opazo-Basáez, M.; Narvaiza, L.; Moya Fernández, P.J. Assessing the effects of human capital composition, innovation portfolio and size on manufacturing firm performance. Compet. Rev. 2021, 31, 625-644. [CrossRef]

12. Vendrell-Herrero, F.; Gomes, E.; Collinson, S.; Parry, G.; Bustinza, O.F. Selling digital services abroad: How do extrinsic attributes influence foreign consumers' purchase intentions? Int. Bus. Rev. 2018, 27, 173-185. [CrossRef]

13. Westerman, G.; Bonnet, D. Revamping your business through digital transformation. MIT Sloan Manag. Rev. 2015, 56, 10.

14. Haro, M.R.D.; Opazo-Basáez, M.; Aranda, D.A. IT implementation and customer results: The mediating role of the competitive priorities achieved by the firm. Int. J. Bus. Environ. 2019, 10, 329-345. [CrossRef]

15. Schroeder, A.; Ziaee Bigdeli, A.; Galera Zarco, C.; Baines, T. Capturing the benefits of industry 4.0: A business network perspective. Prod. Plan. Control 2019, 30, 1305-1321. [CrossRef]

16. Verhoef, P.C.; Bijmolt, T.H. Marketing perspectives on digital business models: A framework and overview of the special issue. Int. J. Res. Mark. 2019, 36, 341-349. [CrossRef]

17. Opazo-Basáez, M.; Vendrell-Herrero, F.; Bustinza, O.F. Uncovering productivity gains of digital and green servitization: Implications from the automotive industry. Sustainability 2018, 10, 1524. [CrossRef]

18. Tan, F.; Tan, B.; Wang, W.; Sedera, D. IT-enabled agility: An interdependencies perspective. Inf. Manag. 2017, 54, 292-303. [CrossRef]

19. Chen, S.Z. Social media: An unmissable opportunity for Chinese enterprises. Mod. Econ. Inf. 2012, 6, 117-118.

20. Montargot, N. Digitalization advances and hospitality service encounters. Symph. Emerg. Issues Manag. 2016, 1, 64-74. [CrossRef]

21. Petrova, K.; Wang, B. Location-based services deployment and demand: A roadmap model. Electron. Commer. Res. 2011, 11, 5-29. [CrossRef]

22. Dhar, S.; Varshney, U. Challenges and business models for mobile location-based services and advertising. Commun. ACM 2011, 54, 121-128. [CrossRef]

23. Zhou, L.; Wang, T. Social media: A new vehicle for city marketing in China. Cities 2014, 37, 27-32. [CrossRef]

24. Wilson, M.W. Location-based services, conspicuous mobility, and the location-aware future. Geoforum 2012, 43, 1266-1275. [CrossRef]

25. Cancino, C.A.; Zurita, G.N. A Location-based Service to support collaboration and strategic control in a Real Estate Broker. In Ubiquitous Computing and Ambient Intelligence, Lecture Notes in Computer Science Series; Springer: Berlin/Heidelberg, Germany, 2017; p. 10586.

26. Dyllick, T.; Muff, K. Clarifying the meaning of sustainable business: Introducing a typology from business-as-usual to true business sustainability. Organ. Environ. 2016, 29, 156-174. [CrossRef]

27. Vendrell-Herrero, F.; Bustinza, O.F.; Opazo-Basaez, M. Information technologies and product-service innovation: The moderating role of service R\&D team structure. J. Bus. Res. 2021, 128, 673-687.

28. Ristova, C.; Dimitrov, N. The value of social media as digital tool in hospitality. Int. J. Inf. Bus. Manag. 2019, 11, 155-162.

29. Bustinza, O.F.; Vendrell-Herrero, F.; Gomes, E.; Lafuente, E.; Opazo-Basáez, M.; Rabetino, R.; Vaillant, Y. Product-service innovation and performance: Unveiling the complexities. Int. J. Bus. Environ. 2018, 10, 95-111. [CrossRef]

30. Mandic, A.; Garbin, D. Progress on the role of ICTs inestablishing destination appeal. Implications for smart tourism destination development. J. Hosp. Tour. Technol. 2019, 10, 791-813.

31. Stankov, U.; Filimonau, V.; Slivar, I. Calm ICT design in hotels: A critical review of applications and implications. Int. J. Hosp. Manag. 2019, 82, 298-307. [CrossRef]

32. Konstantinou, J. Digitalization of European SMEs in Tourism and Hospitality: The Case of Greeks Hoteliers. World Academy of Science, Engineering and Technology. Int. J. Soc. Bus. Sci. 2016, 10, 1558-1562.

33. Popescu, M.; Nicolae, F.; Pavel, M. Tourism and hospitality industry in the digital era: General overview. In Proceedings of the 9th International Management Conference "Management and Innovation for Competitive Advantag", Bucharest, Romania, 5-6 November 2015.

34. SERNATUR. Proyect "Conecta Turismo". Servicio Nacional de Turismo, Sernatur, 2019. Available online: https: / / www.sernatur.cl/subsecretaria-de-turismo-y-sernatur-inician-proyecto-conecta-turismo-con-el-levantamiento-de-desafiosde-digitalizacion-del-sector/ (accessed on 14 January 2020).

35. Bemelmans, J.; Voordijk, H.; Vos, B.; Dewulf, G. Antecedents and benefits of obtaining preferred customer status: Experiences from the Dutch construction industry. Int. J. Oper. Prod. Manag. 2015, 35, 178-200. [CrossRef]

36. Tóth, Z.; Liu, M.; Luo, J.; Braziotis, C. The role of social media in managing supplier attractiveness: An investigation of business-to-business markets. Int. J. Oper. Prod. Manag. 2019, 40, 625-646. [CrossRef]

37. Aral, S.; Dellarocas, C.; Godes, D. Introduction to the special issue-Social media and business transformation: A framework for research. Inf. Syst. Res. 2013, 24, 3-13. [CrossRef]

38. Yin, R.K. Applications of Case Study Research; Sage Publications: Newbury Park, CA, USA, 1993. 
39. Yin, R.K. Case Study Research: Design and Methods; Sage Publications: Thousand Oaks, CA, USA, 1994.

40. Maxwell, J.A. Designing a qualitative study. In Handbook of Applied Social Research Methods; Bickman, L., Rog, D.J., Eds.; Sage Publications: Thousand Oaks, CA, USA, 1998; pp. 69-100.

41. George, A.; Bennett, A. Case Studies and Theory Development in the Social Sciences; MIT Press: Cambridge, MA, USA, 2005.

42. Lam, C.; Law, R. Readiness of upscale and luxury-branded hotels for digital transformation. Int. J. Hosp. Manag. 2019, 79, 60-69. [CrossRef]

43. Schwab, K. The Fourth Industrial Revolution, 1st ed.; Crown Business: New York, NY, USA, 2017.

44. Osterwalder, A.; Pigneur, Y. Business Model Generation: A Handbook for Visionaries, Game Changers, and Challengers; John Wiley and Sons: Hoboken, NJ, USA, 2010.

45. Lemon, K.N.; Verhoef, P.C. Understanding customer experience throughout the customer journey. J. Mark. 2016, 80, 69-96. [CrossRef]

46. Nie, R.X.; Tian, Z.P.; Wang, J.Q.; Chin, K.S. Hotel selection driven by online textual reviews: Applying a semantic partitioned sentiment dictionary and evidence theory. Int. J. Hosp. Manag. 2020, 88, 102495. [CrossRef]

47. Leung, X.Y.; Bai, B.; Stahura, K.A. The marketing effectiveness of social media in the hotel industry: A comparison of Facebook and Twitter. J. Hosp. Tour. Res. 2015, 39, 147-169. [CrossRef]

48. Wang, L.; Law, R.; Guillet, B.D.; Hung, K.; Fong, D.K.C. Impact of hotel website quality on online booking intentions: eTrust as a mediator. Int. J. Hosp. Manag. 2015, 47, 108-115. [CrossRef]

49. Sarmah, B.; Kamboj, S.; Rahman, Z. Co-creation in hotel service innovation using smart phone apps: An empirical study. Int. J. Contemp. Hosp. Manag. 2017, 29, 2647-2667. [CrossRef]

50. Kandampully, J.; Zhang, T.C.; Bilgihan, A. Customer loyalty: A review and future directions with a special focus on the hospitality industry. Int. J. Contemp. Hosp. Manag. 2015, 27, 379-414. [CrossRef]

51. Matt, C.; Hess, T.; Benlian, A. Digital transformation strategies. Bus. Inf. Syst. Eng. 2015, 57, 339-343. [CrossRef]

52. Venkatraman, N. IT-enabled business transformation: From automation to business scope redefinition. Sloan Manag. Rev. 1994, 35, 73-87.

53. Verhoef, P.C.; Broekhuizen, T.; Bart, Y.; Bhattacharya, A.; Dong, J.Q.; Fabian, N.; Haenlein, M. Digital transformation: A multidisciplinary reflection and research agenda. J. Bus. Res. 2021, 122, 889-901. [CrossRef]

54. Verhoef, P.C.; Kannan, P.K.; Inman, J.J. From multi-channel retailing to omni-channel retailing: Introduction to the special issue on multi-channel retailing. J. Retail. 2015, 91, 174-181. [CrossRef]

55. Pagani, M.; Pardo, C. The impact of digital technology on relationships in a business network. Ind. Mark. Manag. 2017, 67, 185-192. [CrossRef]

56. Kazhamiakin, R.; Pistore, M.; Roveri, M. A framework for integrating business processes and business requirements. In Proceedings of the Eighth IEEE International Enterprise Distributed Object Computing Conference EDOC, Monterey, CA, USA, 24 September 2004; pp. 9-20.

57. Ramirez, R.; Melville, N.; Lawler, E. Information technology infrastructure, organizational process redesign, and business value: An empirical analysis. Decis. Support Syst. 2010, 49, 417-429. [CrossRef]

58. Iansiti, M.; Lakhani, K.R. Digital ubiquity: How connections, sensors, and data are revolutionizing business. Harv. Bus. Rev. 2014, $92,19$.

59. Demirbas, U.; Gewald, H.; Moos, B. The impact of digital transformation on sourcing strategies in the financial services sector: Evolution or revolution? In Proceedings of the Twenty-Forth Americas Conference on Information Systems, New Orleans, LA, USA, 16-18 August 2018.

60. Rantala, T.; Ukko, J.; Saunila, M.; Puolakoski, H.; Rantanen, H. Creating sustainable customer value through digitality. World J. Entrep. Manag. Sustain. Dev. 2019, 15, 325-340. [CrossRef]

61. Kane, G.C.; Palmer, D.; Phillips, A.N.; Kiron, D.; Buckley, N. Strategy, Not Technology, Drives Digital Transformation; MIT Sloan Management Review and Deloitte University Press: Cambridge, MA, USA, 2015; Volume 14, pp. 1-25.

62. Rotondo, F.; Fadda, N. The influence of being part of a tourist network on hotels' financial performance. Int. J. Hosp. Manag. 2019, 82, 335-344. [CrossRef]

63. Koo, B.; Yu, J.; Han, H. The role of loyalty programs in boosting hotel guest loyalty: Impact of switching barriers. Int. J. Hosp. Manag. 2020, 84, 102328. [CrossRef]

64. Delpechitre, D.; Beeler-Connelly, L.L.; Chaker, N.N. Customer value co-creation behavior: A dyadic exploration of the influence of salesperson emotional intelligence on customer participation and citizenship behavior. J. Bus. Res. 2018, 92, 9-24. [CrossRef]

65. Sousa, M.J.; Santo, V.; Sacavém, A.; dos Reis, I.P.; Sampaio, M.C. 4.0 Leadership skills in hospitality sector. J. Rev. Glob. Econ. 2019, 8, 105-117. [CrossRef]

66. Martin, J.F. Unlocking Success in Digital Transformations; McKinsey \& Company: New York, NY, USA, 2017. Available online: https:/ / www.mckinsey.com/ \{\}/media/McKinsey/Business\%20Functions/Organization/Our\%20Insights/Unlocking\% 20success\%20in\%20digital\%20transformations/Unlocking-success-in-digital-transformations.ashx (accessed on 1 July 2020).

67. Evans, N. Assessing Your Organization's Digital Transformation Maturity. 2017. Available online: https://www.cio.com (accessed on 18 February 2020).

68. Lobschat, L.; Mueller, B.; Eggers, F.; Brandimarte, L.; Diefenbach, S.; Kroschke, M.; Wirtz, J. Corporate digital responsibility. J. Bus. Res. 2021, 122, 875-888. [CrossRef] 
69. Hemerling, J.; Kilmann, J.; Danoesastro, M.; Stutts, L.; Ahern, C. It's Not a Digital Transformation without a Digital Culture; Boston Consulting Group: Boston, MA, USA, 2018.

70. Robbins, S.; Coulter, M. Management, 14th ed.; Pearson: New York, NY, USA, 2018.

71. Von Leipzig, T.; Gamp, M.; Manz, D.; Schöttle, K.; Ohlhausen, P.; Oosthuizen, G.; Palm, D.; von Leipzig, K. Initialising customer-orientated digital transformation in enterprises. Procedia Manuf. 2018, 8, 517-524. [CrossRef]

72. Schein, E.H. Organizational Culture and Leadership; John Wiley \& Sons: Hoboken, NJ, USA, 2010.

73. Fitzgerald, M.; Kruschwitz, N.; Bonnet, D.; Welch, M. Embracing digital technology: A new strategic imperative. Mit Sloan Manag. Rev. 2013, 55, 1-12.

74. Haynes, P.; Fryer, G. Human resources, service quality and performance: A case study. Int. J. Contemp. Hosp. Manag. 2000, 12, 240-248. [CrossRef]

75. Warner, K.S.; Wäger, M. Building dynamic capabilities for digital transformation: An ongoing process of strategic renewal. Long Range Plan. 2019, 52, 326-349. [CrossRef]

76. Svahn, F.; Mathiassen, L.; Lindgren, R. Embracing Digital Innovation in Incumbent Firms: How Volvo Cars Managed Competing Concerns. MIS Q. 2017, 41, 239-253. [CrossRef]

77. Arkhipova, D.; Bozzoli, C. Digital Capabilities. In CIOs and the Digital Transformation; Bongiorno, G., Rizzo, D., Vaia, G., Eds.; Springer: Cham, Switzerland, 2018.

78. Prihanto, J.J.N.; Kurniasari, F. Sustainable Digital Transformation in the Hospitality Industry: A Study of the Hotel Industry in Indonesia. In Proceedings of the 2019 International Conference on Organizational Innovation (ICOI 19), Ulsan, Korea, 20-22 July 2019; Atlantis Press: Paris, France, 2019.

79. Bass, B.M.; Bass, R. The Bass Handbook of Leadership: Theory, Research, and Managerial Applications; Simon and Schuster: New York, NY, USA, 2009. 